International Journal of Engineering \& Technology, 7 (4) (2018) 2628-2632
International Journal of Engineering \& Technology
SPC
Website: www.sciencepubco.com/index.php/IJET
doi: $10.14419 /$ ijet.v7it.12763
Research paper

\title{
An ultra-wide band printed small aperture tapered slot phased array antenna covering 6-18GHZ
}

\author{
G. NagaPavani ${ }^{1 *}$, Ch. Lakshmi Prasanna ${ }^{2}$, Dr. N. N. Sastry ${ }^{3}$ \\ ${ }^{I}$ M.TECH student, VR Siddhartha Engineering College \\ ${ }^{2}$ Senior Research fellow \\ ${ }^{3}$ Professor, Dean R\&D \\ *Corresponding author E-mail: prasu474@gmail.com
}

\begin{abstract}
For phased array applications covering ultra wide bandwidth, it is necessary to restrict the size of the aperture to less than $\lambda / 2$ at highest frequency of operation. For $6-18 \mathrm{GHz}$ coverage, an aperture size of less than $9.76 \mathrm{~mm}$ is required for scanning to \pm 450 without appearance of grating lobes and occurrence of element pattern nulls over the band. Meeting this requirement a printed tapered slot antenna has been designed with the above aperture size. Detailed parametric studies have been carried out over 6-18 GHz and dimensions have been opti-mized for return loss. The design has been carried out with HFSS software. A return loss of less than -7.5dB across $5.6-20 \mathrm{GHz}$ has been obtained for a single antenna. Also satisfactory radiation patterns have been obtained.
\end{abstract}

Keywords: Ultra Wideband; Phased Arrays; Printed Tapered Slot Antenna; Parametric Analysis; Grating Lobes.

\section{Introduction}

Ridged horns, Equiangular spirals, Archimedean spirals, Log periodic antennas and some planar slot loaded printed antennas have been used for large bandwidth applications. Tapered slot antennas (TSA) and their variants have recently come into focus particularly for wideband phased array applications. Some ridge gap wave guide designs have also been reported in literature. For Communications and EW applications covering frequency range of 1 $18 \mathrm{GHz}$ and for use in phased arrays several variants of TSA have been successfully used. For operation over $6-18 \mathrm{GHz}$ in phased arrays which is the bandwidth of interest in this paper, the spacing between elements should be less than about $0.586 \lambda_{\mathrm{h}}$, where $\lambda_{\mathrm{h}}$ is the wavelength corresponding to the highest frequency, for scanning to $\pm 45^{\circ}$, and for avoidance of grating lobes and element pattern nulls. The spacing between the elements for this condition should be no more than $9.76 \mathrm{~mm}$. With this spacing at $6 \mathrm{GHz}$, the spacing between the elements becomes $0.195 \lambda_{\mathrm{L}}$, where $\lambda_{\mathrm{L}}$ is the wavelength corresponding to lowest design frequency. Vivaldi radiators can easily be made to operate from $8-18 \mathrm{GHz}$ with this spacing and a return loss of less than $-10 \mathrm{~dB}(\mathrm{VSWR}=2.0)$ can be obtained with satisfactory radiation patterns. At lower than $8 \mathrm{GHz}$ the resistive part of the input impedance becomes very small resulting in large VSWR. In the following paragraphs printed multi octave band phased array antennas are surveyed.

Nurad and MIT jointly developed a 3:1 and 9:1 bandwidth dual polarized planar phased arrays using Vivaldi antenna [1]. The 9:1 array is reported to be operating over $2: 18 \mathrm{GHz}$ with an inter element spacing of $7.5 \mathrm{~mm}$. In this paper, an overview of the development is given without much dimensional details. In another paper, a wideband Vivaldi antenna array with a 5:1 bandwidth intended for radio astronomy applications is reported [2]. A phased array with 3:1 bandwidth has been described in literature with a frequency range of $6-18 \mathrm{GHz}$ and scanning to $\pm 45^{\circ}$ [3].
A dual polarized Vivaldi antenna with capability for wide angle scanning has also been reported. This antenna covers $6-18 \mathrm{GHz}$. Only simulations have been reported using FDTD technique [4]. In another design, Antipodal Vivaldi antenna using parasitic elliptic patch has been designed. This has an aperture size of $66 \mathrm{~mm}$ covering $6-21 \mathrm{GHz}$ [5]. A $2.4 \mathrm{GHz}$ to $18 \mathrm{GHz}$ antenna with an aperture size of $44 \mathrm{~mm}$ is also found in literature [6].

A BAVA antenna with an aperture size of $14.5 \mathrm{~mm}$ operating over $3-9 \mathrm{GHz}$ has been reported [7]. Another BAVA antenna with an aperture size of $44 \mathrm{~mm}$ covering $1-20 \mathrm{GHz}$ can be found in literature [8]. A multi octave band antipodal Vivaldi antenna with a return loss of less than $-7.5 \mathrm{~dB}$ and an aperture size of $20 \mathrm{~mm}$ has also been reported [9]. This is the largest bandwidth of $1-40 \mathrm{GHz}$ reported with an aperture size of $20 \mathrm{~mm}$. A novel, small aperture tapered slot antenna has been reported covering 7.2-18.0 GHz with a return loss of less than $-7.5 \mathrm{~dB}$ in simulation and with frequency coverage of $7.7-18.0 \mathrm{GHz}$ in hardware with an aperture size of $9.5 \mathrm{~mm}$ [10].

It can be seen from the above, that almost all the printed antennas excepting one or two designs have an aperture size of more than $20 \mathrm{~mm}$ and therefore are not suitable for phased array applications for scanning to $\pm 45^{\circ}$ and for a frequency coverage of $6-18 \mathrm{GHz}$. The Nurad antenna cited above is reportedly the only printed antenna covering 6-18GHz with a VSWR of less than 2.0.

In view of the above, the authors have designed a modified Vivaldi antenna which yielded a return loss of less than $-7.5 \mathrm{~dB}$ over 6 $18 \mathrm{GHz}$ using HFSS software and satisfactory radiation patterns have been obtained. The reference antenna for this design is the small aperture antenna with a $9.5 \mathrm{~mm}$ aperture cited above [10].

\section{Antenna geometry}

The sketch of the antenna is shown in Fig.1. The antenna is designed using a substrate with a dielectric constant of 3.66. The 
antenna has two substrates joined together. The top one is a Vivaldi Tapered slot antenna (TSA) having exponential taper with a sinusoidal function superimposed on it. The slot is terminated at the backend by two circular slots and is excited by a microstrip line located on the bottom substrate. The input power is electromagnetically coupled to the narrow slot having TSA. This input micro stripline is terminated in a sectoral stub. Optimization of various parameters has been done which is given below and has led to a frequency coverage of $6-18 \mathrm{GHz}$.

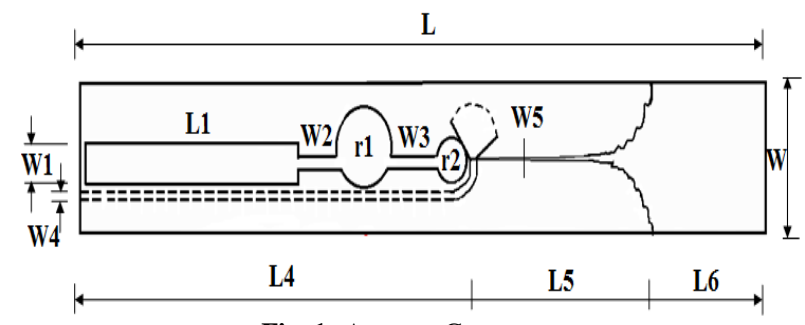

Fig. 1: Antenna Geometry.

\section{Parametric studies}

Referring to Fig 1. some of the important parameters that have been varied to achieve a bandwidth of $6-18 \mathrm{GHz}$ with a return loss of less than $-7.5 \mathrm{~dB}$ are given below.

- Growth rate of the exponential taper superimposed by a sinusoidal function ' $a$ '

- Circular cavity radius ' $r_{2}$ '

- Line width ' $\mathrm{W}_{3}$ ' between first and second circular cavities

- Circular cavity radius ' $r_{1}$ '

- Line Width ' $\mathrm{W}_{2}$ ' between stub and first circular

- cavity

- $\quad$ Length of the slot line stub ' $\mathrm{L}_{1}$ '

- Width of the stub ' $\mathrm{W}_{1}$ '

- Extension of substrate beyond the taper ' $\mathrm{L}_{6}$ '.

With the above parametric variation the dimensions have been optimized to achieve $6-18 \mathrm{GHz}$ coverage with a return loss of less than $-7.5 \mathrm{~dB}$ and these are given at table 1 .

\subsection{Return loss variation with growth rate 'a'}

Initial design specifications derived from the reference paper [10] are

$\mathrm{L}=50 \mathrm{~mm}, \mathrm{~L}_{1}=17.0 \mathrm{~mm}, \mathrm{~W}_{1}=2.0 \mathrm{~mm}, \mathrm{~W}_{2}=\mathrm{W}_{3}=0.7 \mathrm{~mm}, \mathrm{r}_{1}=2.3 \mathrm{~mm}$, $\mathrm{r}_{2}=1.38 \mathrm{~mm}, \mathrm{a}=0.7$.

Firstly, keeping all the other variables constant as given above, the exponential growth rate of the tapered slot (a) is varied from 0.2 to 0.9 and return loss curves are obtained. However growth rate variation from 0.5 to 0.9 is only shown in Fig. 2 for clarity. Others have not yielded desired bandwidth and hence omitted. $\mathrm{a}=0.6$ yielded a return loss of less than $-5 \mathrm{~dB}$ over [6-18] $\mathrm{GHz}$ which is the optimum value.

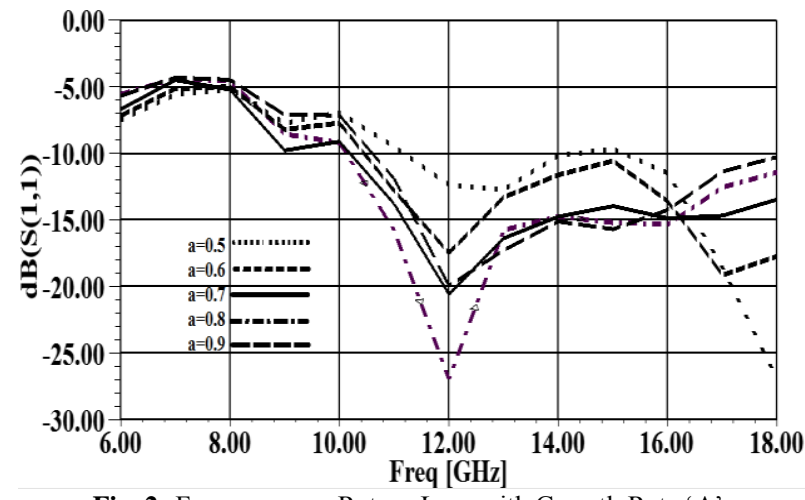

Fig. 2: Frequency vs. Return Loss with Growth Rate 'A'.

\subsection{Return loss variation with circular cavity radius ' $r 2$ '}

Second circular cavity radius $r_{2}$ is varied from $1.38 \mathrm{~mm}$ to $1.45 \mathrm{~mm}$ Substantial variation of return loss is observed between $11 \mathrm{GHz}$ to $16 \mathrm{GHz}$. while a resonant behavior is observed at $12 \mathrm{GHz}$. Return loss is less than $-7.5 \mathrm{~dB}$ from $7.5 \mathrm{GHz}$ to $18 \mathrm{GHz}$ for $\mathrm{r}_{2}=1.42 \mathrm{~mm}$.

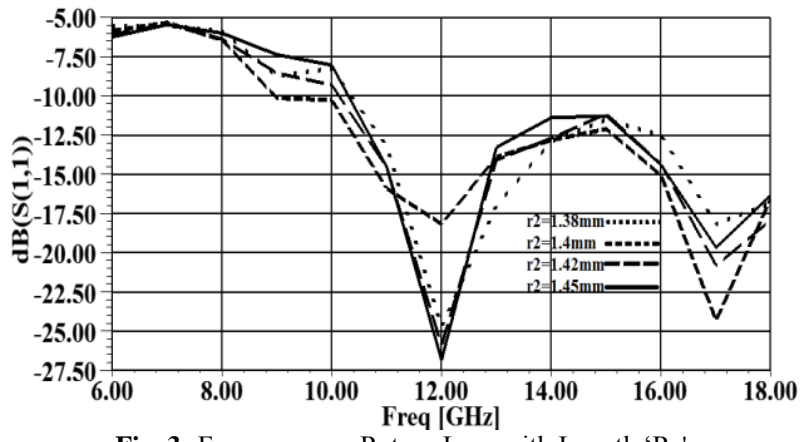

Fig. 3: Frequency vs. Return Loss with Length ' $R_{2}$ '.

\subsection{Return loss variation with width of the stub ' w3'}

The spread in the variation is maximum at $12 \mathrm{GHz}$, where a resonance is observed. The solid curve with $\mathrm{w}_{3}=0.69 \mathrm{~mm}$ gives maximum bandwidth with a return loss of less than $-7.5 \mathrm{~dB}$ over $7.7 \mathrm{GHz}$ to $18 \mathrm{GHz}$.

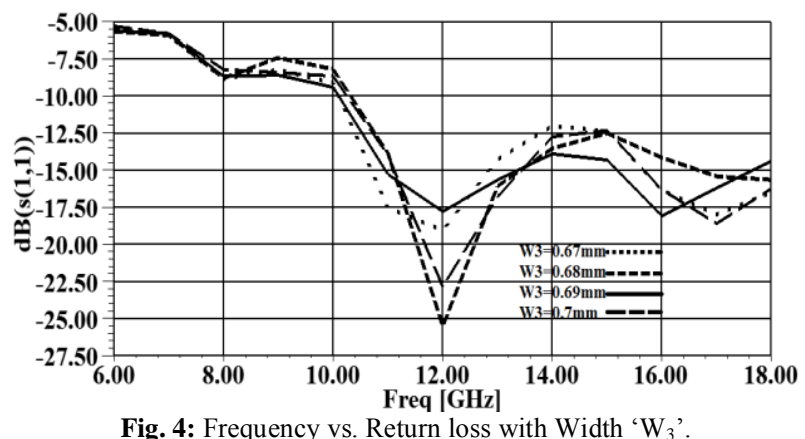

\subsection{Return loss variation with circular cavity radius ' $r 1$ '}

Return loss curves are similar to that of variation with respect to $r_{2}$ given above. Once again a resonance is obtained at $12 \mathrm{GHz}$. It can be observed that spread in the curves is much less compared to $r_{2}$ variation shown in Fig3. The solid curve with $r_{1}=2.6 \mathrm{~mm}$ gives the maximum frequency bandwidth with a return loss less than $-7.5 \mathrm{~dB}$ between $7.6 \mathrm{GHz}$ to $18 \mathrm{GHz}$.

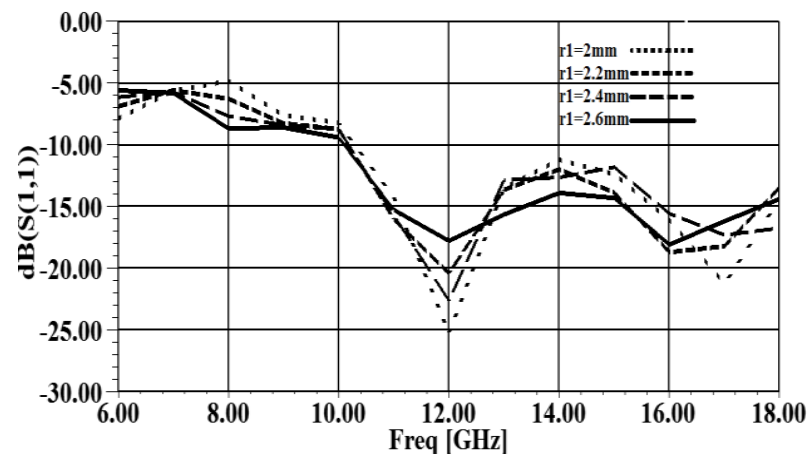

Fig. 5: Frequency vs. Return Loss of Radius 'R1'.

\subsection{Return loss variation with 'w2'}

From Fig. 6 it is clear that there is a resonance occurring at $12 \mathrm{GHz}$ and $17 \mathrm{GHz}$. The solid curve with $\mathrm{w}_{2}=0.68 \mathrm{~mm}$ gives the largest bandwidth with a return loss of less than $-7.5 \mathrm{~dB}$ from $7.9 \mathrm{GHz}$ to $18 \mathrm{GHz}$. 


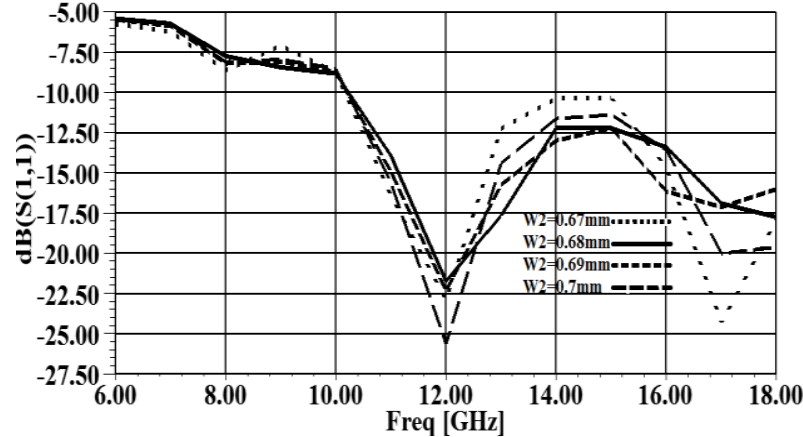

Fig. 6: Frequency vs. Return Loss of Line Width ' $\mathrm{W}_{2}$ '.

\subsection{Return loss variation with length of the stub 'L1'}

$\mathrm{L}_{1}$ is varied from $18.0 \mathrm{~mm}$ to $19.3 \mathrm{~mm}$. There is no significant variation of return loss with $\mathrm{L}_{1}$ over $8 \mathrm{GHz}$ to $18 \mathrm{GHz}$. However, at lower frequencies between $6 \mathrm{GHz}$ and $8 \mathrm{GHz}$, there is substantial variation in the return loss. The solid curve with $\mathrm{L}_{1}=19.3 \mathrm{~mm}$ gives the optimum result with a return loss $-7.5 \mathrm{~dB}$ over $6-18 \mathrm{GHz}$ (Fig.7).

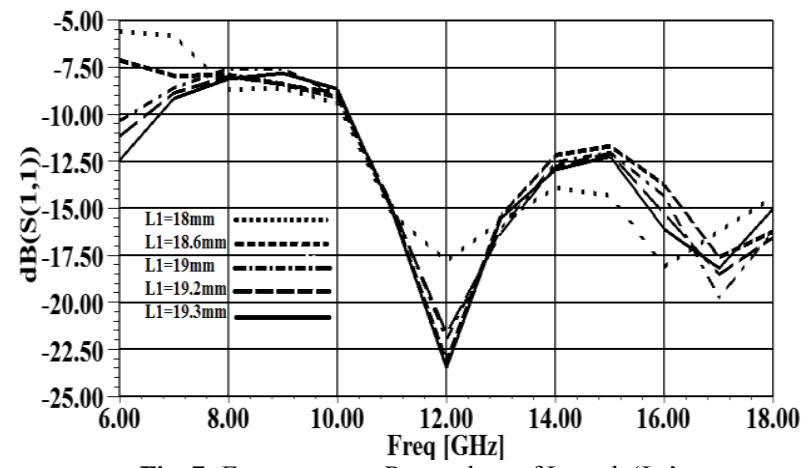

Fig. 7: Frequency vs. Return loss of Length ' $\mathrm{L}_{1}$ '.

\subsection{Return loss variation with width 'w1'}

The width of the stub is varied from 2.0 to $2.6 \mathrm{~mm}$. The resonance is observed at $12 \mathrm{GHz}$. Similar but less significant resonances are observed at $8 \mathrm{GHz}$ and $16 \mathrm{GHz}$. The spread in the return loss variation is maximum at $12 \mathrm{GHz}$. The solid curve with $\mathrm{w}_{1}=2.6 \mathrm{~mm}$ gives the optimum result with return loss of $-7.5 \mathrm{~dB}$ from $7.7 \mathrm{GHz}$ to $18 \mathrm{GHz}$.

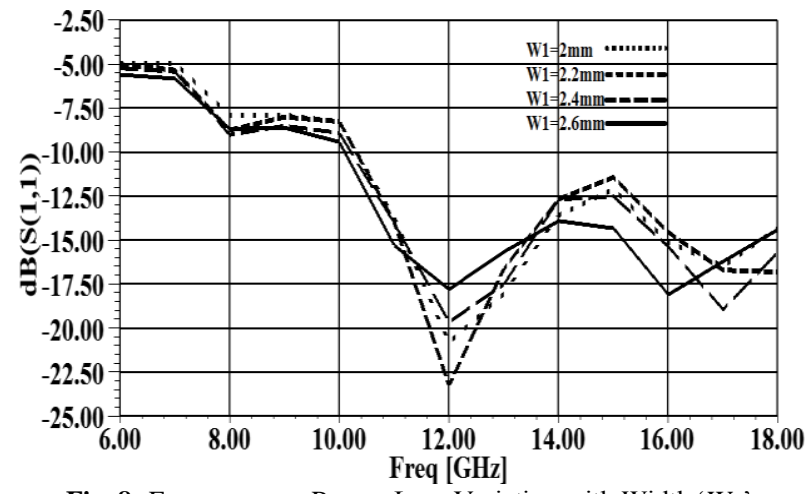

Fig. 8: Frequency vs. Return Loss Variation with Width ' $\mathrm{W}_{1}$ ',

\subsection{Return loss variation with dielectric extension '16'}

This is a novel introduction in this paper. This has substantial effect on return loss as can be seen from the curves. $\mathrm{L}_{6}$ is varied from $2.0 \mathrm{~mm}$ to $6.0 \mathrm{~mm}$ and the largest bandwidth with less than $8 \mathrm{~dB}$ return loss is obtained for $\mathrm{L}_{6}=10 \mathrm{~mm}$.

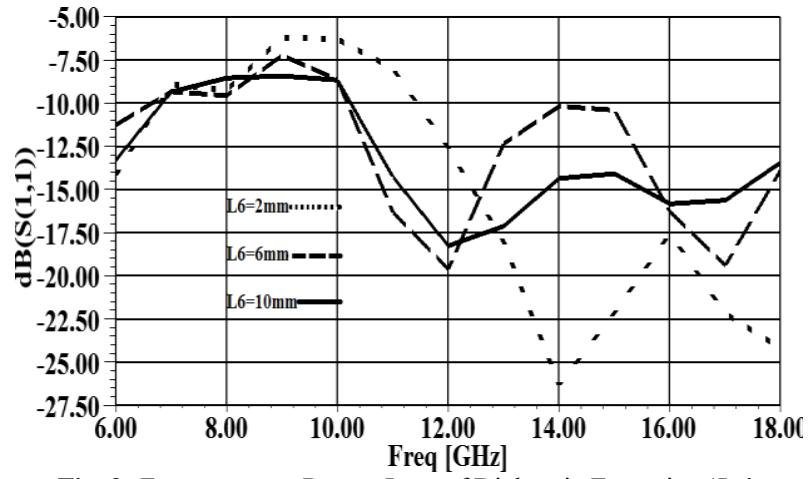

Fig. 9: Frequency vs. Return Loss of Dielectric Extension ' $L_{6}$ '.

\section{Results}

With the above optimization of various parameters a return loss of less than $-7.5 \mathrm{~dB}$ over $5.6-20 \mathrm{GHz}$ is observed. The optimized dimensions are given in table 1 .

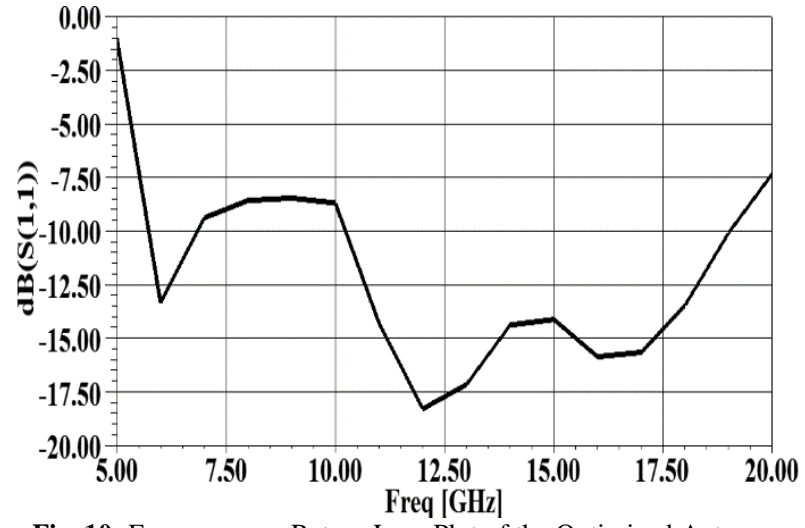

Fig. 10: Frequency vs. Return Loss Plot of the Optimized Antenna.

Table 1: Optimum Dimensions

\begin{tabular}{llll}
\hline Parameter & Value $($ in $\mathrm{mm})$ & Parameter & Value $($ in $\mathrm{mm})$ \\
\hline L & 63.0 & W2 & 0.69 \\
W & 9.5 & W3 & 0.68 \\
L1 & 19.3 & W4 & 0.544 \\
W1 & 2.6 & W5 & 0.2 \\
r1 & 2.6 & L4 & 34.0 \\
r2 & 1.45 & L5 & 18.0 \\
L2 & 2.7 & L6 & 10.0 \\
\hline
\end{tabular}

Gain is variation over $6-20 \mathrm{GHz}$ is plotted in Fig.11. Gain varies from $-10 \mathrm{~dB}$ at $5 \mathrm{GHz}$ to $+5.8 \mathrm{~dB}$ at $20 \mathrm{GHz}$.

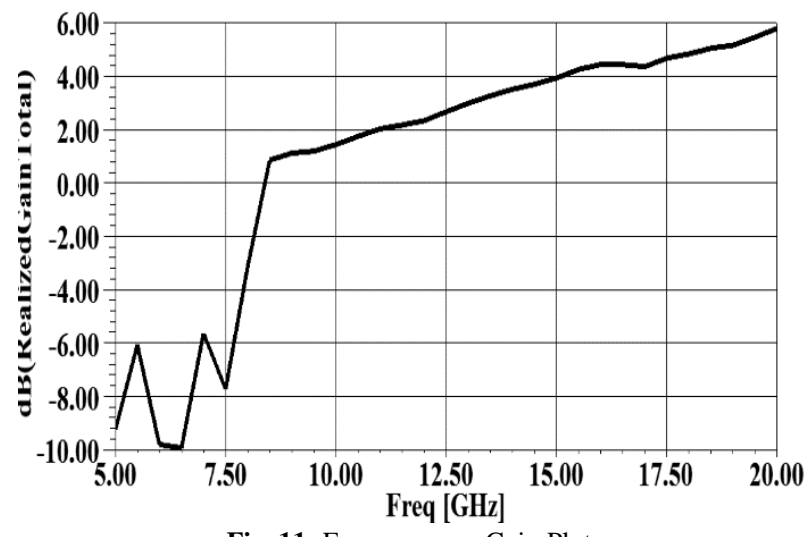

Fig. 11: Frequency vs. Gain Plot.

Radiation patterns of E-plane (solid line) and H-plane (dotted line) are shown in Fig.12 (a-g). It is observed that the radiation patterns are regular and satisfactory over $6-20 \mathrm{GHz}$ frequency range. 
(A) At 5.6 GHZ

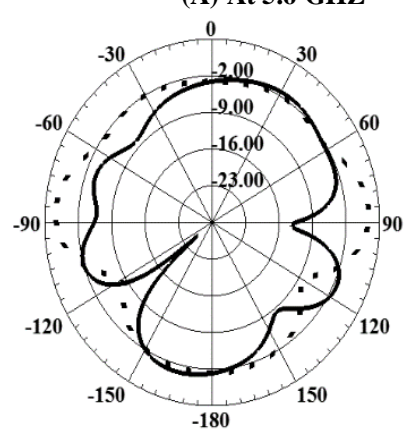

(B) At $6 \mathrm{Ghz}$

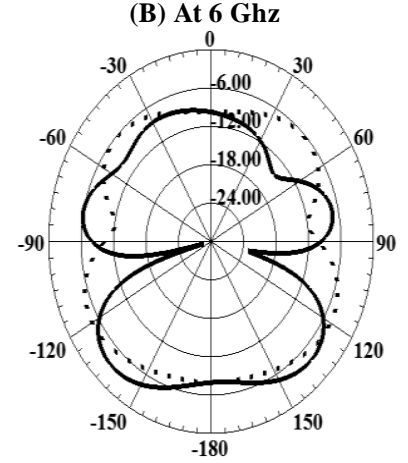

(C) At $10 \mathrm{Ghz}$

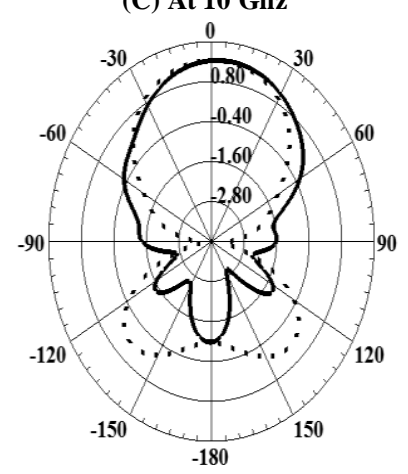

(D) At 14 GHZ

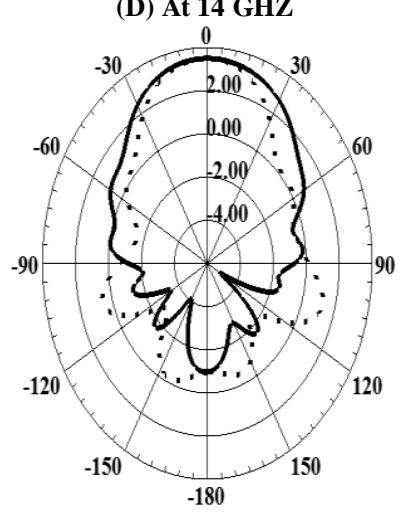

(E) At 16 GHZ

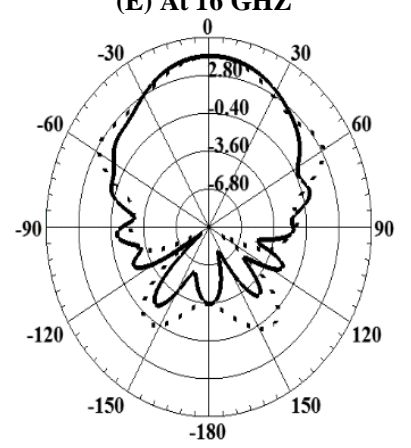

(F) At 18 GHZ

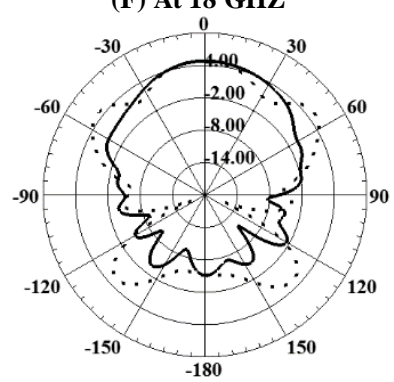

(G) At 20 GHZ

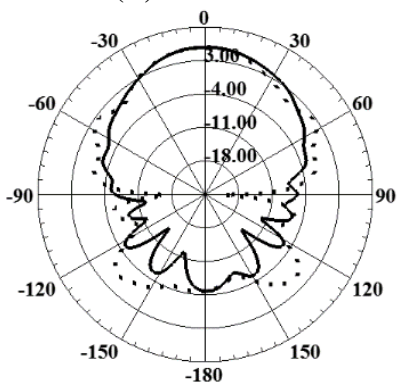

Fig. 12: Radiation Patterns of the Simulated Antenna.

\section{Conclusion}

A modified Vivaldi radiator with an aperture size of $9.5 \mathrm{~mm}$ has been designed using ANSYS HFSS software. This antenna has an exponential taper with a novel sinusoidal function superimposed on it. In addition to this two substrates are used which are joined together each having a dielectric constant of 3.66 and a thickness of $0.5 \mathrm{~mm}$. Beyond the tapered portion dielectric is extended to obtain desired bandwidth. Parametric studies have been carried out on all the important parameters of the antenna design. These optimization studies have resulted in a design having a return loss of less than $-7.5 \mathrm{~dB}$ over $5.6-20 \mathrm{GHz}$ with satisfactory radiation patterns.

\section{Acknowledgement}

The authors are thankful to DRDO-EMR Directorate, New Delhi for supporting this design and analysis study. They are also thankful to Mr. M. Balachary Associate director DLRL, DRDO for continuous support. They are thankful to Dr. A. V. Ratna Prasad principal and Dr. K. Sri Rama Krishna Head ECE Department of VR Siddhartha Engineering College for constant encouragement.

\section{References}

[1] Mike Stasiowski, Dan Schaubert, "Broadband array antenna" Proc.2008, Antenna Applications Symposium, pp.72-59, December 2008, Monticello II.

[2] Daniel. H. Schaubert, Tan-Huat Chio, "Wideband Vivaldi arrays for large aperture antennas", Perspectives on Radio astronomyTechnologies for Large Antenna arrays, Netherlands Foundation for Research in Astronomy - 1999.

[3] Junyeon Kim, Joonho So, Won Jang and Changyul Cheon, "Design of Wideband phased array antenna using Ridged Tapered Slot antenna", conference on Antennas and Propagation society international symposium 2006 IEEE.

[4] C.B.Wyllie, G.M.Lewis and R.A.Lewis, "Dualpolar vivaldi antennas for phased arrays with wide angle scanning", 11th International Conference on Antennas and Propag, pp.72-676, 17-20 April 2001, UK.

[5] Ibrahim T. Nassar and Thomas M. Weller, "A Novel method for Improving Antipodal Vivaldi Antenna Performance", IEEE Trans on Antennas and Propag, Vol.63, no.7, July 2015.

[6] Jeremie Bourqui, Michal Okoniewski, Elise. C. Fear," Balanced Antipodal vivaldi antenna with Dielectric director for Near-field. 
[7] Microwave Imaging", IEEE Trans on Antennas and Propag, Vol. 58, no.7, July 2010.

[8] W.J.Otter, B.P.Pirollo, R.I.Henderson and R.A.Lewis,"Multi octave BAVA radiating elements for use in Modular phased array antennas", third European conference on Antennas and propagation 2009.

[9] Bayat, A. and R. Mirzakhani, "A parametric study and design of the balanced antipodal Vivaldi antenna (BAVA)," PIERS Proceedings, 778-782, Moscow, Russia, August 19-23, 2012.

[10] James Fisher," Design and Performance analysis of a $1-40 \mathrm{GHz}$ ultra wideband antipodal Vivaldi antenna", German Radar Symposium GRS 2000, Berlin, Germany.

[11] K. Sneha and Dr. N. N. Sastry,"A Small Aperture Multi Octave Band Tapered Slot Radiator ", Antennas and Propagation in Wireless Communications (APWC), 2017 IEEE-APS Topical Conference, Verona, Italy. 